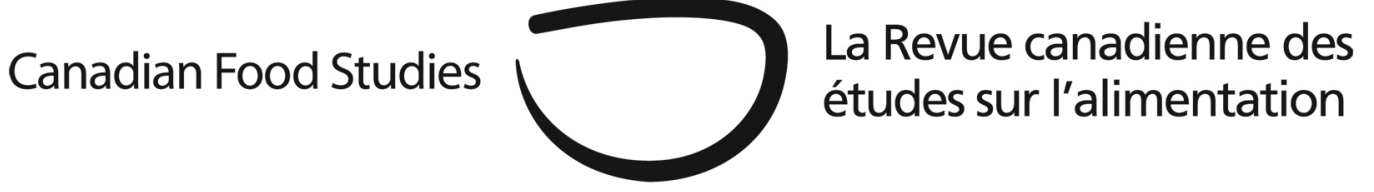

\title{
Editorial
}

\section{Perceptions and practices in an evolving food system}

\author{
Ellen Desjardins
}

It is serendipitous when a series of submissions to the journal seem to embed a similar theme. In this issue we present several original research articles that offer critical, in-depth analyses of evolving practices in various "alternative" food settings, coupled with perceptions among farmers, retailers, and consumers about their roles and choices in this ever-changing milieu. We are very pleased that two of these articles are based on research from Québec, written in French. They originate from a two-day symposium in Montréal in May, 2016, on the topic of alternative food systems. A synopsis of this conference is provided in this issue as an event review by Boulianne and Mundler.

Newman, Powell, Nickel, Anderson, Jovanovic, Mendez, Mitchell, and Kelly-Freiberg take us to the agriburbs of Vancouver, where they have investigated the gradual marketing shifts among four farm stores that have embraced the "rural idyll" of urban consumers, or romanticization of farm life. Maltais, for his part, presents the gentrification of small urban food shops in Montréal that have repositioned themselves as "alternative", catering increasingly to consumers who prefer more locally-sourced niche products. In both cases, the supportive public and higher profits represent a beneficial side of these increasingly multifunctional enterprises; nevertheless, both researchers' findings also include on-going challenges and critical perspectives.

On the eastern side of the country, MacLeod brings us the second stage of her ethnographic research with Cape Bretoners, documenting perceptions of farming and personal identities tied up with their experience of the ecological food movement. Similar to the previously-mentioned authors, she identifies both negative and positive aspects of this movement—steering us away from ideology and towards reality. The survey-based study of Baumann, Engman, Huddart-Kennedy, and Johnston in Toronto also reveals greater complexity among the drivers of consumer perceptions and choices of local and organic food. 
It becomes clear, from this collective research-derived from the voices of producers, sellers and eaters in longitudinal studies - that the meanings of food can be transformed, and that these meanings can in turn transform food operations, networks, and even identities. Doyon's study illustrates this perfectly: over time, the common eel and sturgeon fish caught in the St. Lawrence River estuary have become in-demand status food, leading to efforts to certify it as PGI (protected geographical indication). She asks the critical questions: Would this type of certification, applied to local fish, help build its image as alternative? Would it contribute to an alternative distribution network? She argues that it's not simple, and that historical, social, political and economic aspects of fisheries management must be reviewed before decisions are made.

Tourangeau's analysis takes research on influencing public perceptions to a deeper epistemological level. Focusing on discourses meant to inform the public about the merits_-and non-merits - of GMOs, he compares anti-biotech campaigns materials with what might be termed the "GMO doublespeak" of a government backed industry. He offers critical insights on how power can be exerted in subtle ways, and reveals the underlying power imbalances embedded in the strategic use of language-for example, with the appeal to values such as "feeding the poor" and "protecting the planet".

Food insecurity is also the offspring of systemic power imbalances, including those inherent in academic institutions which tend to ignore the nourishment needs of students. Entz, Slater, and Desmarais have studied food insecurity at the University of Manitoba, according to perceptions of post-secondary students, and suggest, in turn, systemic solutions.

We urge you to forage through the book reviews, both English and French, of recent works by Lenore Newman, Caroline Durand, and Guptill, Copelton, and Lucal. The "shepherding" of submissions in French has been made possible by the addition of Natalie Doonan, of Montréal, as our newest associate editor, in January 2017. We welcome Natalie to the team.

The editorial team appreciates their continued collaboration with the CAFS Journal Governance Committee, established in June 2016: Rebecca Schiff, Lenore Newman, Jennifer Brady, and Kristin Lowitt. We thank the University of Waterloo for providing our OJS online platform, plus essential library staff support.

2017 Editorial Team:

Ellen Desjardins, PhD, Editor edesjardins@canadianfoodstudies.ca

Wesley Tourangeau, PhD, Managing Editor wtourangeau@canadianfoodstudies.ca

Alyson Holland, PhD, Associate Editor eholland@canadianfoodstudies.ca 
Natalie Doonan, PhD, Associate Editor ndoonan@canadianfoodstudies.ca

Phil Mount, PhD, Associate Editor pmount@canadianfoodstudies.ca

David Szanto, PhD, Associate Editor dszanto@canadianfoodstudies.ca

Rod MacRae, PhD, Associate Editor rmacrae@yorku.ca 